Article

\title{
Navigating Urban Life in Lisbon: A Study of Migrants' Mobilities and Use of Space
}

\author{
Franz Buhr* and Jennifer McGarrigle \\ Institute of Geography and Spatial Planning, University of Lisbon, 1600-276 Lisbon, Portugal; E-Mails: fbuhr@campus.ul.pt \\ (F.B.), jcarvalho@campus.ul.pt (J.M.) \\ * Corresponding author
}

Submitted: 15 July 2017 | Accepted: 20 September 2017 | Published: 28 December 2017

\begin{abstract}
Besides a more general concern over transport infrastructure, its quality and availability, mobility is also a pre-condition for city dwellers to access urban resources, facilities, employment, local services and leisure. Moreover, mobility allows urban inhabitants to uncover a city's potentialities and to fully participate in urban life. Migrants, nevertheless, face the issue of learning to do mobility in a new environment together with the urgency for settlement, finding work, making personal connections and attending to the mundane needs of everyday life that require one to move about. This article looks at migrants' urban mobilities in Lisbon, Portugal, from two perspectives. First, we look at migrants' urban knowledge and skills and at how they employ their abilities to use Lisbon's urban resources. Second, we address some of the ways placespecific urban resources of a religious nature sustain and are sustained by various (im)mobility practices. More specifically, we look to a suburban mosque run by Guinean migrants and to a Sikh Gurdwara. This mobile/place-based contrast points to the variegated (and often overlooked) forms of mobility (or lack of) that are put to practice by migrants and to how they shape the everyday of migration journeys and their capacities to enjoy city-living.
\end{abstract}

\section{Keywords}

integration; migrant; mobility; navigation; religion; transport; urban; wellbeing

\section{Issue}

This article is part of the issue "Regional and Urban Mobility: Contribution to Social Inclusion", edited by Janet Stanley (University of Melbourne, Australia) and John Stanley (University of Sydney, Australia).

(C) 2017 by the authors; licensee Cogitatio (Lisbon, Portugal). This article is licensed under a Creative Commons Attribution 4.0 International License (CC BY).

\section{Introduction}

The challenges and possibilities associated with living in cities have gained momentum within social scientific research. Although the urban form has been a longstanding source of debate in scholarly accounts, it seems that what is particularly new about a recent trend in urban writings has to do with a perceived need to understand and analyse the mobilization of hitherto 'academic' concepts and ideas by urban populations themselves as they growingly frame their claims and complaints by recourse to terms such as, for example, 'the right to the city' or 'gentrification'. The ways these once academiconly concepts have reverberated into social debates and media coverage opens up a whole research agenda signalling a renewed interest for the urban question that has transcended academia and been incorporated into the grammar of everyday city living.

A key debate regarding dwelling in urban settings is that of how people move about in space. Urban mobility has figured in many academic and non-academic accounts which problematize, for instance, the sustainability of driving cultures, claims for the creation or improvement of cycling and other alternative transport infrastructures, or the footprint of everyday transit and so on. Yet, urban mobility has a less visible (and far less studied) side which is its intersection with migrant integration concerns. As urban inhabitants, immigrants confront 
many of the urban issues met by native populations, but they also face the question of learning to do mobility in a new environment together with the urgency for settlement, finding work, making personal connections and attending to the mundane needs of everyday life that require one to move about.

It is this interface between urban mobility and migrant integration that we address in this article. We depart from the premise that the making of urban mobilities is a fundamental aspect to be taken into account when thinking about migrants' urban lives. Urban mobility, as we reflect in the following paragraphs, is both a primary need for migrants to access urban resources and services, as it is also a producer of migrants' social and spatial connectedness toward the city. Mobility is a means to an end, but, as the 'new mobilities' paradigm has put it (Sheller \& Urry, 2006), it is also more than that: it creates socialities, affinities, knowledge and, for these reasons, it may help us look at migrant emplacement from a mobile vantage point.

We structured the article along the following lines. First, we present some of the ways in which urban mobility has intersected with migration and integration scholarship. We focus on empirically informed studies which provide tools for linking urban mobility and migrants' wellbeing. Second, we present our two case studies from Lisbon, Portugal. The first case study looks at migrants' urban mobilities as a learned skill and, in so doing, unpacks the ways mobility knowledge materializes into specific mobility practices. We rely on qualitative data produced by migrants of various origins and situate it in the context of their urban expertise. Participants were recruited as to ensure a broad spectrum of migration profiles (origins, length of stay, neighbourhood of residence, etc.), responded to in-depth interviews, drew mental maps and completed time-space diaries. The second case study addresses some of the ways place-specific urban resources of a religious nature sustain and are sustained by various (im)mobility practices. More specifically, we look to a suburban mosque run by Guinean migrants and to a Sikh Gurdwara. We explore how the Islamic community on the city's edge provides in situ social solidarity as a way to circumvent both social and spatial exclusion in the light of mobility constraints. In contrast, we turn to the Gurdwara to unpack its role as a place of connection in shaping Punjabi migrants' residential and everyday mobilities. This mobile/place-based contrast aims to elucidate the variegated (and often overlooked) forms of mobility (or lack of mobility) that are put to practice by migrants and how they shape the everyday of migration journeys and their capacities to enjoy city-living. The article ends with a brief reflection on the potentialities afforded by this perspective.

\section{Migration, Urban Mobility and Wellbeing}

Since the 'mobility turn', the social sciences have moved away from viewing urban mobilities as mere byproducts of social life to looking at them as producers of complex spatial and social configurations. Opening the 'black box' of mobilities has not only brought to light the activities that take place during movement ('dwelling in motion'), but, by considering mobility as an activity in itself, revealed that 'mobilities are everywhere' (Cresswell, 2006) and that we should pay close attention to the complex interdependencies between, and social consequences of, such diverse mobilities' (Urry, 2000, p. 185).

Although migration scholars seem not to have 'bought into' the mobilities paradigm in its entirety (King, 2012 , p. 143), there is a growing body of research on the nexus between urban mobility and migrant integration. A frequent claim is that moving about is how migrants become 'grounded in the local through their everyday practices' (van Riemsdijk, 2014, p. 963). Van Riemsdijk (2014), for example, has looked at place-making and explored how urban geographies and belonging are intertwined for skilled migrants in Oslo. Myers (2008) addressed the performative aspect of emplacement among asylum seekers in Plymouth. Her research pointed to the ways through which ordinary skills such as wayfinding and orientation function as important homing devices for recently arrived individuals. Sampson and Gifford (2010) have focused on settlement processes of young refugees in Melbourne and on how their moving through urban space afforded remedies for previous traumatic experiences, something they named 'therapeutic landscapes'.

The proliferation of terms such as migrant emplacement, groundedness, situatedness or spatial integration, all aiming to grasp the variegated relationships between migrants and their presence in and movement through local territories testify to the critical roles everyday geographies play in settlement processes, as emotional geographies (Davidson, Bondi, \& Smith, 2007) are constructed and homeliness is ascribed to new localities (Ahmed, Castañeda, Fortier, \& Sheller, 2003). Although this growing body of research has opened the 'black box' of migrants' urban mobilities, we believe that not enough attention has been accorded to the link between migrants' urban mobilities and the material urgencies of settlement, such as finding accommodation, work, or simply learning to navigate a still unfamiliar territory. While most studies tend to focus on the creation of affective ties between migrants and their place of settlement (place-making, home-making, belonging, identity etc.), we direct our attention here to the practicalities of emplacement.

These (perhaps more) immediate needs, or preconditions for city-living, have been investigated from other angles and in other literatures, not necessarily pertaining to immigrant integration concerns. Studies on mobilities and wellbeing, for instance, have advanced relevant lines of enquiry that may be applied to contexts where migrant integration is aimed. As Stanley, Hensher, Stanley and Vella-Brodrick (2011) have noted, 'wellbeing is not just something people desire because it feels good, but also because it is associated with a range of 
other highly valued outcomes', which may range from health and social interaction to having access to relevant resources and services, housing and professional occupation. Such 'openness' of wellbeing research to social and individual outcomes that involve both the use and the navigation of urban life can, in turn, help to frame some of the preoccupations of migration and integration scholarship.

Urban space and the ways it is practised have ranked high in specialized literature as determinant aspects of wellbeing. As Schwanen and Wang (2014, p. 835) argue, several research projects have shown that factors such as density, degree of urbanization, city size and accessibility to transport infrastructure are indicators of urban wellbeing, although results differ across studies. Transport mobility is often considered a key indicator and has been explored in many contexts, although research has almost exclusively employed samples of older people (Stanley et al., 2011, p. 790). A growing consensus points to the need to widen the populations and groups studied (and include women, children, ethnic minorities, etc.), as to account for intersectional causation, but also to undertake more close-up accounts of the ways urban mobility conditions inhabitants' engagements with the urban resources and experiences deemed relevant by individual participants, rather than the ones defined a priori by experts (Nordbakke \& Schwanen, 2014, p. 107).

This article responds to a perceived call for more nuanced, qualitative explorations of inhabitants' mobilities. As we delve into the 'mechanics' (Knowles, 2010) of migrants' spatial practices in Lisbon, our aim is to understand how migrants provide themselves with a certain number of urban resources (Asselin, Dureau, Giroud, Hamadi, \& Marcadet, 2005, p. 64). As we demonstrate in the following sections, considering migrants as urban inhabitants who, in different ways and resorting to various (mobility) strategies, do manage to live urban lives is to accord them their agency as city dwellers, without producing voluntarist narratives of migrant integration. To unpack the knowledge and skills employed by migrants to find jobs or affordable accommodation, or to circumvent spatial exclusion, postcode discrimination or neighbourhood stigma, for instance, is to engage analytically with structural constraints, if only from the perspective of those affected by such issues.

A crucial concern for both migration and wellbeing scholarships is the individual's ability to manage basic everyday needs by recourse to urban mobility. Knowles and Harper (2009), for example, have shown how the navigational aspects of British migrants journeying through Hong Kong unravel their social worlds and expose their spatialities of privilege, Whiteness and lifestyle migration. Parallel to that, within wellbeing research, Ryff (1989) contended that finding and creating a surrounding context suiting one's personal needs and capacities (Nordbakke \& Schwanen, 2014, p. 111)-what Ryff called 'environmental mastery' - was one of the six key dimensions of wellbeing. What links these contributions to- gether is an understanding of the human-environment interaction that acknowledges individuals' capacities to mobilize a city's resources as their own resources, which suggests a 'softening' of the boundary between self and space. As urban space and its resources and capacities enter the realm of 'what is within reach' (as opposed to 'what is out there'), individuals are able to work urban space from within. In fact, Seamon (1979, p. 101) had already described such process as a tendency towards mergence, because there is a break in the boundary between person (self) and world (non-self); in figurative terms, the person merges with his [sic] environment'.

Such sensitivity to one's surroundings is learned through action, Seamon argues, 'Movements become familiar when the body performs them several times and incorporates them' (1979, p. 48). Borrowing from Merleau-Ponty's Phenomenology of perception (1962), where the author states that:

Motility, then, is not, as it were, a handmaid of consciousness, transporting the body to that point in space of which we have formed a representation beforehand. In order that we may be able to move our body towards an object, the object must first exist for it, our body must not belong to the realm of the 'initself'. (1962, pp. 138-139)

Seamon argued that such mergence leads to a sense of 'at-easiness' impacting individuals' wellbeing and quality of life. In other words, it is the active practising of urban space through mobility that enables city-dwellers, migrants or non-migrants, to develop a practical resourcefulness, with which they become equipped to tackle the demands of everyday life. Yet, the experiences afforded by urban space may also impact the long haul of migration journeys, as we will show later in the article.

Mobility, as this article contends, plays a critical role in allowing for that state of mergence, or integration. We will now proceed our empirical illustrations in a twofold way: first, we show how migrants mobilize knowledge and skills in order to do mobilities; second, we look at how migrants convoke urban mobilities in order to carry out activities and attend to the urgencies of settlement.

\section{Lisbon Tricks: Urban Skills and Migrants' Mobilities}

This section explores the links between migrants' urban knowledges and how they crystalize into particular forms of doing mobility. We address more specifically the embodied knowledges articulated by migrants in Lisbon and the extent to which they retranslate into urban practices and experiences. We do so by resorting to a qualitative, EU-funded fieldwork carried in Lisbon in 2015 and 2016 for which 25 migrants of various origins, ethnicities and socio-economic and legal statuses were inquired through in-depth interviews, mental maps and time-space journals. Participants were selected following a purposivesampling logic, as one of our aims was to understand 
how the various and overlapping categories of migrant integration research (such as age, gender, nationality, education, occupation, etc.) played out in migrants' urban geographies of practice. All the interviews which appear in this article were conducted in Portuguese.

When we first introduced the topic of our research project to Tiago, a national of Sao Tome and Principe living in Lisbon since 2008, he immediately told us about the first time he took a train in Lisbon. Having only used the metro before, he expected the train's doors also to open automatically, which they did not. 'No one left at that station so the doors kept shut and I missed my stop' he said laughing. 'That was something I quickly learned; I'll never forget it'. These banal practicalities of public transit, as they ingrain themselves into urbanites' ways of moving about, constitute part of the unreflexive practice of everyday life (Binnie, Edensor, Holloway, Millington, \& Young, 2007). Anecdotal when seen as an isolated event, these mobility skills add up to afford urbanites a sense of 'at-easiness' with urban space that Seamon (1979) held to be a crucial signifier of human spatial integration.

But Tiago's stories of navigating Lisbon also brought to light some of the intricacies between urban mobilities and questions of race and (postcolonial) migration:

I was never the kind of person that hangs out where there's only white people.... only go to the bars where there are other black fellows. If there are two bars one next to the other and in one there are blacks and in the other whites, of course I go to the black one; if I can help a fellow African, of course I will. This whole racism and xenophobia thing is something that only those (Africans) who have been here for a long time have experienced. That is because they arrived at a time where there were very few black people here. Today, if you don't want to be humiliated you always have an option: there's a black bar and a white bar. Period.

Tiago's account is not only a story of ethnic solidarity, but one of a racialized city where he performs racial mobilities in order to avoid being discriminated against. As Knowles (2003, p. 42) has argued, ethnicity is also construed 'in a moving sense of place and social landscape'. Mobility here-and knowing where there are 'black bars' and how to find them-is part of a repertoire of spatial strategies mobilized by Tiago as a way to access an African/hospitable Lisbon. His racialized geographies involve the places he prefers to go to, but also those which he avoids. Martim Moniz, the most ethnically diverse neighbourhood in central Lisbon, happens to be one of such places. Tiago used to visit a friend who lived there and was searched by the police a couple of times, "hands on the wall and everything' as he said, 'that's why I try not to go there anymore'. The very notion of embodied knowledge could not be more literal than in this case where Tiago's body was inspected by police officers who imprinted a 'no-go zone' onto his personal geographies.
Doing mobility always entangles practical knowledge, which is produced, learnt and mobilized by urban dwellers. Nevertheless, mobility knowledge does not always retranslate into actual mobility practices. In a study conducted with Korean Christian immigrant women living in Los Angeles, Shin (2011, p. 2356) noticed how 'these women's mobility resources, such as cars and knowledge, are not transformed into freedom of mobility for them'. Shin argued that both the specificities of Los Angeles' urban structure and the highly structured and gendered roles these women lived did not leave much room for experiencing freedom in urban mobility despite their possession of significant mobility potential or, as Kaufmann (2002) defines it, motility.

A similar argument may be used to describe the feeling of 'entrapment' experienced by Zie, a Chinese woman living in Portugal since 2002. Zie runs a convenience store and a restaurant with her husband. During our conversation, she demonstrated a deep understanding of which were the best and the worst neighbourhoods in Lisbon to open a Chinese restaurant and a shop. Zie herself admitted often going to other similar shops owned by Chinese migrants in Lisbon to see the level of prices practised. Despite this fine business-oriented reading of Lisbon neighbourhoods, Zie told us she hardly ever leaves her own neighbourhood.

I live 10 minutes from here [the shop]. Walking. We park the car in front of the shop. The restaurant is just over there....All must be very close. The schools [where her children study], the shop.... know this area very well.

When asked if she would like to live elsewhere in Lisbon, Zie replied 'no, no; I prefer to live close to the shop'. It is evident that for her spatial proximity between work and home is more than a mere preference; it frames her and her family's activity orbit: they all live, work, study and shop within a $1 \mathrm{~km}$ radius. And although in the past Zie had explored the commercial potentialities of other districts in Lisbon, nowadays she does not feel confident and has no need to actually trespass this limited, yet familiar territory. So much so that when asked about the two neighbouring districts (both within less than a 15minute walk from her shop), Zie said 'I don't know them. It's just work and home'. Despite the specific reasons leading to Zie's 'entrapped' spatial practices (and their particular consequences), her condition might be paired with that of older Portuguese residents, mainly the ones living in the historical neighbourhoods in Lisbon, where restrictions to mobility (both in terms of physical capacities and transport infrastructure) have kept elderly populations isolated from the rest of urban life and, therefore, heavily dependent on care and external support, a topic always in vogue in local news.

On a different note, Jessica, a Cape Verdean dentist, experiences a radical disjunction between home and the workplace. Her many residential mobilities and various 
workplaces (both previous and contemporary) located in non-contiguous neighbourhoods in Lisbon have forced her to rely on a car for everyday mobility. 'I try to avoid driving whenever I can, I really like walking, but going to one workplace to the other and carrying my materials with me is something I could not do without a car', she said. The quotidian crisscrossing of Lisbon has made Jessica develop a rich repertoire of routes and places. When asked to draw a mental map of the Lisbon she used, Jessica drew the following image (Figure 1).

At the centre of her 'map', she locates her home neighbourhood. From that starting point, she selects and organizes areas in Lisbon based on her practical needs: to the left, she lists the places she goes to for a night out; in the centre, where she goes shopping; on the top right, she arranged the places she frequents for leisure activities; and finally, on the bottom right, the two clinics where she works at the moment.

Rather than a representation of Lisbon's landscape, Jessica's scheme is better understood as a taskscape, a term coined by Ingold (1993) to describe the tapestry of dwelling activities, which sew together time and space. Jessica's drawing is the product of the sum of various journeys accumulated in time, exposing her habitual practices and choices. Her selecting, emphasizing, reorienting and juxtaposing of urban resources testify to her ability do 'bend' urban space to a given purpose (Buhr, 2017a), making it a function of her own needs.

The three examples presented here provide a glimpse into the relationship between the making of migrants' mobilities in Lisbon and the mobilization of practical knowledges and skills. It matters how we get to places (Ahmed, 2006), and looking at the ways migrants do mobilities exposes how they manage everyday urban life in the face of the various structural limitations faced, such as racism, spatial entrapment, urban functional zoning and home/workplace disjunction, for instance. This perspective illuminates the question of migrant integration and its intersections with well-being and spatial confidence (Koskela, 1997), as migrants narrate, whether through interviews or drawings, what they actively do with urban space, in order to enjoy it or to circumvent its constraints.

\section{Faith-Based Urban Resources: Place and (Im)Mobility}

In this section, we explore the links between migrants' urban mobilities, faith and place-based urban resources and the material needs of everyday life. We draw on fieldwork, carried out between 2012 and 2014, in the ambit of a wider research project. In particular, we look at life in and around two migrant places in the city-a Sikh Gurdwara and a suburban mosque ${ }^{1}$-and reflect on some of the ways they respond to migrants' mobility practices and facilitate migrant emplacement in the city.

We turn first to the suburban mosque, located in a suburb at the very extension of Lisbon's urban sprawl. The pioneer West African Muslim migrants we interviewed moved to this area in the 1990s, attracted by lower house prices and employment in construction in the municipality. These residential spatial patterns are closely related with the specific phase of urban expansion at their time of arrival in the city. At the time, residential mobility to the suburb signified a positive integration trajectory and accumulation of assets as many bought their own homes facilitated by easy access to credit. It was in one of these homes that the mosque first began, until the local Muslim population outgrew the space. It now occupies a converted garage in a rear courtyard blurring the line between secular and sacred space. The lack of signing or symbolism means the only visible indications of the significance of the place are the religious rituals and practices of local Muslims that flow over

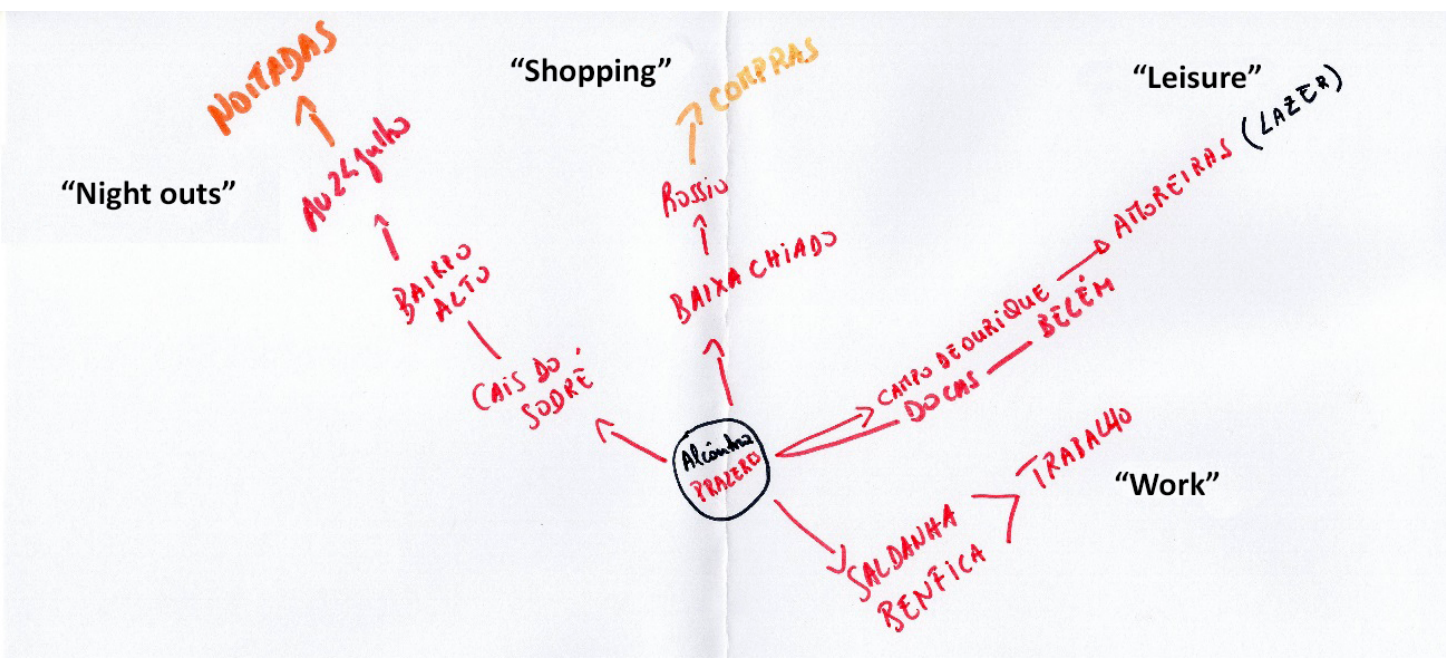

Figure 1. Jessica's mental map.

\footnotetext{
${ }^{1} 25$ in-depth interviews were conducted in the former and 39 in the latter.
} 
into the public sphere, such as lingering after prayers or discarded shoes on the street. After family reunification, the needs of everyday life became more spatially anchored. As the religious leader describes, a sister association was established in the same square to provide faith-based welfare provision in compensation for rudimentary social services (Ley, 2008; Winkler, 2008), and to address specific migrant needs.

We arrived to the area and there were things missing, our children were with us, wives, we began to think of the future. First about Islam, but this wasn't enough. I'm not very well educated, my son has homework and I can't help. We saw many difficulties and we needed a place to meet them.

Early mobility to the suburban periphery spatially matched employment opportunities in construction. However, in the aftermath of the economic crisis, in which the construction sector was severely affected, the spatial context offered little flexibility to pursue work opportunities elsewhere. A growing sentiment of isolation or spatial de-connectedness from the city was evident in the narratives of the interviewees. In the context of high levels of unemployment, transport become unaffordable and distance increased in a time-space decompression.

Now I feel trapped here, I could jump the ticket barrier and, I do sometimes, but I'm afraid of getting caught and being landed with a fine. Transport is too expensive. I can't afford the train to go to Lisbon.

Access to informal employment networks was hindered and a perceived spatial mismatch between residence and employment opportunities was central in the interviewees' accounts:

You can't arrange work here anymore. You need to go to Lisbon just to look for work, to go and come back takes so much time and money! If I could I would move to Amadora [an intermediate municipality before the city of Lisbon]. Someone there would pass me information about a job because there is a lot of movement there. It's a meeting place, not just for Guineans but loads of nationalities.

The narratives above demonstrate not only the critical role of the spatial context in understanding mobility capacity, but also the importance of individual sociostructural embeddedness. Furthermore, the gap that can exist between knowing how to do mobility and being able to do it attests to mobility as 'a structuring dimension of social life' (Kaufmann, Bergman, \& Joye, 2004, p. 754).

As lessening urban mobility circumscribed everyday geographies to the neighbourhood, new local spatialities and knowledge developed, with the mosque assuming particular importance, as Ibrahim describes:
Now that I don't work, I know the neighbourhood inside out, upside down. Before it was just on Saturday and Sunday, I was only here on the weekend, I didn't really pay attention to the place....It won't do to enter into the café here. I go in and the owner asks "yes, do you need something?" Then I can only stay here on the street, in the shopping centre. So I end up spending my time in the mosque, then going for a walk.

Mobility was not only affected at the local level, but across scales as economic marginalization, in some instances, led to onward migration reiterating other findings (McGarrigle, 2016; Esteves, Fonseca, \& Malheiros, 2017). Edmundo told us that 'there are many empty homes in the area; they left for the UK, Germany'. In contrast, various interviewees described the in-situ social support from the mosque and Islamic association. This helped to alleviate hardship in the short-term but not fundamentally change it due to the scope of intervention at the very local level. Intra-community social solidarity came in different forms as evident in the following accounts:

I am sick, or I miss or can't buy my medicines, so they talk in the mosque....Pull together, and get what I need.

I stayed in the mosque at the beginning after they closed my house and I cleaned it in exchange.

They offer me food, vegetables, rice, spaghetti. I never imagined my life would come to this.

I get help here to deal with my social welfare papers without having to travel to Sintra.

Despite the physical restrictions on mobility and dependence on local community support, entrapment propelled spatial imaginaries beyond the limits of the everyday. Vincent, who had migrated from Guinea Conakry in the early 2000s, elaborates:

All the work that we came here for has stopped. All I can think about is my "terra," I wouldn't be so touched there, even in a crisis, my mum and dad are there, family to support me. I imagine being with my family working in the fields.

The same sentiments were present in other interviewees' discourses, which encompassed narratives of return and onward migration.

Now turning to the Sikh Gurdwara, the first point of contrast is its accessibility. In 2010, the Gurdwara moved to a new location, in a vacant factory, close to the last stop on the metro line, which connects directly to the city. As one leader elaborates:

We felt the first location [of the Gurdwara] was much too far for people to get to, they had to walk for ages. We looked for something close to a metro stop so that people can come more easily and more frequently. 
The relocation of the Gurdwara brings to mind Ingold's (2006) assertion that place does not exist as location but as the juncture of different trajectories-in this case encompassing day-to-day and migration journeys. Indeed, the Gurdwara is a site where the local arrangements of everyday life in Lisbon are negotiated, responding to the primary needs of new migrants arriving to the city to find work and accommodation. Networking with local Punjabi business men and other migrants provides an entry point into the urban labour market (McGarrigle \& Ascensão, 2017). One interviewee described this in the following way:

The first port of call is to the place in the city where you know you will receive help, with a job, a house and the rest.

It functions in a network of places, as a node or muscular matter where many tendons connecting to other spaces dispersed across the city converge-namely places of work, which include grocery, phone shops and restaurants. Of course, support is available in situ through cultural and religious resources and practices such as langar, which provides the community with daily food. However, the local employment networks that intersect in the Gurdwara produce new spatial behaviour and urban mobilities. In contrast with the very local reach of the welfare offered by the suburban mosque, the urban resources obtainable at the Gurdwara result in the creation of new routes through the city and networked territories that enmesh ethnic solidarity with the vulnerability of newly arrived migrants. Of course, this is precisely due to differences in modes of labour market insertion between both groups. In practice, business owners, who rely on new migrants as a source of low-cost labour, define the rules of initial movement. For instance, Ritam was introduced to a restaurant owner through contacts made at the Gurdwara when he first arrived in Lisbon.

I moved to Paço de Arcos [an area on the Lisbon coast/estuary] with my boss, another cook and a chef, all together in the same house. It was a big house. Our boss paid everything, rent, we ate at the restaurant, we worked every day it was really complicated.

Later after gaining new skills and abilities to navigate the city and the urban labour market, Ritam moved further out of the city to Cascais on the coast then to the city centre, where he continues to work in an Indian restaurant. His residential mobility made him more aware of urban borders, between the inner city and the suburbs, and different diurnal rhythms, opening up new possibilities for him in the city. He began to explore the nighttime city and try out nightlife in the bars and clubs of downtown Lisbon. His more experimental urban experience uncovers the variegated places in which migrant identities unfold, showing the multiplicity of migrant spatialities (Brickell \& Datta, 2011; Kochan, 2016). Again,
Ritam illustrated this when spoke of how he manages cultural and religious expectations with his experimental experiences.

I only have Sunday free, that's when I go to the Gurdwara. I wake at 9.00 and then after 2 or 3 in the afternoon I take a bath and then later I go out with my friends, to drink. But in the Gurdwara I never say, nobody says.

His range of spatial connections involve skill and negotiation-in this case the boundaries of religious expectations.

The two migrant places of worship we explored in this section both operate as urban service hubs for different groups of migrants, yet they are distinctive due to their different spatial reach. While this highlights the critical role of the spatial context in understanding mobility capacity, such contexts are not ahistoric and have been produced by conditions of arrival and the distinct modes of incorporation and organization of both communities in the city.

\section{Conclusions}

We have seen that mobilities may serve different functions to migrant urbanites and how using certain key urban resources often implies the production of particular circuits and circulations that entangle ethnic/religious solidarity, similar spatial positionalities, or the need to satisfy common everyday needs, for example. Yet, the practice of urban mobility is not a given, as if it were readily (and equally) accessible to everyone to answer to the problem solving requirements of everyday urban life. Mobility is also something we learn to do and that requires a constant manipulation and re-adjustment of skills and knowledge (Buhr, 2017b).

Nevertheless, as the examples provided here indicate, while competence is essential for doing mobility, practical knowledge does not inevitability result in mobility practice. Looking at mobility potential, or motility, can certainly reveal important aspects relating to quality of life and wellbeing (Kaufmann et al., 2004, p. 753), but it is the examination of both mobility potential and actual mobility practices that provides a more thorough account of the ways migrants do manage to navigate urban life even when facing various forms of urban inequality.

Thinking about migrant emplacement in terms of individuals' capacities to mobilize a city's resources as their own resources has allowed us to grasp migrants' active roles in terms of managing the urgencies of settlement, but also the constraints and opportunities often materialized in the shape of urban structure, residential location, and their own positionalities within their networks and within the socio-economic spectrum. In fact, some of our findings have shown how contextual change (i.e., economic crisis), inasmuch as it impacted migrants' mobility practices and limited access to services and provi- 
sions, also re-shaped migrants' migratory plans to a point where onward migration appeared as a possible solution.

To excavate the interface between urban mobility and migrant integration is to open up avenues for thinking what migrants need urban space for but also what kinds of resources and possibilities cities make available for them. Tracing migrants' urban mobilities exposes a complex relationality between self and environment and directs our attention to the everyday, banal requirements of urban life that are, nevertheless, the very substance of migrant integration.

\section{Acknowledgements}

The research leading to these results has received funding from the Portuguese Foundation for Science and Technology (FCT) [grant number PTCD/CS-GEO/ 113680/2009] and from the European Union's Seventh Framework Programme (FP7/2007-2013) [grant number 316796].

\section{Conflict of Interests}

The authors declare no conflict of interests.

\section{References}

Ahmed, S. (2006). Queer phenomenology: Orientations, objects, others. Durham: Duke University Press.

Ahmed, S., Castañeda, C., Fortier, A.-M., Sheller, M. (Eds.). (2003). Uprootings/regroundings. Questions of home and migration. Oxford: Berg.

Asselin, O., Dureau, F., Giroud, M., Hamadi, A., Marcadet, Y. (2005). Access to urban resources as a spatial expression of social integration. In L. Fonseca \& J. Malheiros (Eds.), Social integration and mobility: Education, housing and health. IMISCOE Cluster B5 State of the Art Report (pp. 56-72). Lisbon: CEG.

Binnie, J., Edensor, T., Holloway, J., Millington, S., \& Young, C. (2007). Mundane mobilities, banal travels. Social \& Cultural Geography, 8(2), 165-174.

Brickell, K., \& Datta, A. (2011). Translocal geographies. Spaces, places, connections. Farnham: Ashgate.

Buhr, F. (2017a). Using the city: Migrant spatial integration as urban practice. Journal of Ethnic and Migration Studies. https://doi.org/10.1080/1369183X. 2017.1341715

Buhr, F. (2017b). A user's guide to Lisbon: Mobilities, spatial apprenticeship and migrant urban integration. Mobilities. http://dx.doi.org/10.1080/17450101. 2017.1368898

Cresswell, T. (2006). On the move: Mobility in the modern western world. London: Routledge.

Davidson, J., Bondi, L., \& Smith, M. (2007). Emotional geographies. London: Ashgate.

Esteves, A., Fonseca, L., \& Malheiros, J. (2017). Labour market integration of immigrants in Portugal in times of austerity: Resilience, in situ responses and re- emigration. Journal of Ethnic and Migration Studies. http://dx.doi.org/10.1080/1369183X.2017.1346040

Ingold, T. (1993). The temporality of landscape. World Archaeology, 25(2), 152-174.

Ingold, T. (2006). "Up, across and along." Place and location. Studies in Environmental Aesthetics and Semiotics, 5, 21-36.

Kaufmann, V. (2002). Re-thinking mobility. Burlington: Ashgate.

Kaufmann, V., Bergman, M., \& Joye, D. (2004). Motility: Mobility as capital. International Journal of Urban and Regional Research, 28(4), 745-756.

King, R. (2012). Geography and migration studies: Retrospect and prospect. Population, Space and Place, 18, 134-153.

Knowles, C. (2003). Race and social analysis. London: Sage.

Knowles, C. (2010). Mobile sociology. The British Journal of Sociology, 373-379.

Knowles, C., \& Harper, D. (2009). Hong Kong: Migrant lives, landscapes, and journeys. London: University of Chicago Press.

Kochan, D. (2016). (Re)placing migrants' mobility: A multi-method approach to integrating space and mobility in the study of migration. Migration Studies, 4(2), 215-237.

Koskela, H. (1997). 'Bold walk and breakings': Women's spatial confidence versus fear of violence. Gender, Place and Culture, 4(3), 301-310.

Ley, D. (2008). The immigrant church as an urban service hub. Urban Studies, 45(10), 2057-2074.

McGarrigle, J. (2016). Islam in urban spaces: The residential incorporation and choices of Muslims in Lisbon. Journal of Ethnic and Migration Studies, 42(3), 437-457.

McGarrigle, J., \& Ascensão, E. (2017). Emplaced mobilities: Lisbon as a translocality in the migration journeys of Punjabi Sikhs to Europe. Journal of Ethnic and Migration Studies. http://dx.doi.org/10.1080/ 1369183X.2017.1306436

Merleau-Ponty, M. (1962). Phenomenology of perception. New York: Humanities Press.

Myers, M. (2008). Situations for living: Performing emplacement. Research in Drama Education: The Journal of Applied Theatre and Performance, 13(2), 171-180.

Nordbakke, S., \& Schwanen, T. (2014). Well-being and mobility: A theoretical framework and literature review focusing on older people. Mobilities, 9(1), 104-129.

Ryff, C. (1989). Happiness is everything, or is it? Explorations on the meaning of psychological well-being. Journal of Personality and Social Psychology, 57, 1069-1081.

Sampson, R., \& Gifford, S. (2010). Place-making, settlement and well-being: The therapeutic landscapes of recently arrived youth with refugee backgrounds. Health \& Place, 16, 116-131. 
Schwanen, T., \& Wang, D. (2014). Well-being, context, and everyday activities in space and time. Annals of the Association of American Geographers, 104(4), 833-851.

Seamon, D. (1979). A geography of the lifeworld. Movement, rest and encounter. London: Croom Helm.

Sheller, M., \& Urry, J. (2006). The new mobilities paradigm. Environment and Planning A, 38, 207-226.

Shin, H. (2011). Spatial capability for understanding gendered mobility for Korean Christian immigrant women in Los Angeles. Urban studies, 48(11), 23552373.

Stanley, J., Hensher, D., Stanley, J., \& Vella-Brodrick, D.
(2011). Mobility, social exclusion and well-being: Exploring the links. Transportation Research Part A, 45, 789-801.

Urry, J. (2000). Mobile sociology. British Journal of Sociology, 51(1), 185-203.

van Riemsdijk, M. (2014). International migration and local emplacement: Everyday place-making practices of skilled migrants in Oslo, Norway. Environment and Planning A, 46(4), 963-979.

Winkler, T. (2008). When God and poverty collide: Exploring the myths of faith-sponsored community development. Urban Studies, 45(10), 2099-2116.

\section{About the Authors}
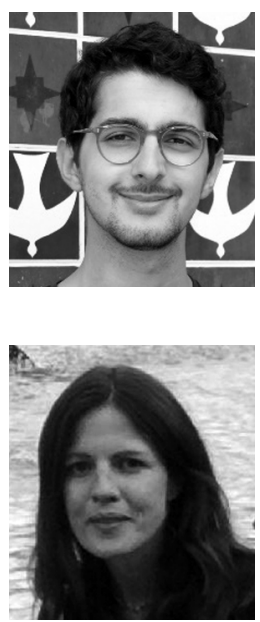

Franz Buhr is a Marie Curie Research Fellow in the framework of the INTEGRIM project. He is based at the Institute of Geography and Spatial Planning (IGOT) at the University of Lisbon.

Jennifer McGarrigle holds a PhD in Urban Studies from the University of Glasgow, UK. She is an Assistant Professor in Human Geography at the Institute of Geography and Spatial Planning (IGOT) at the University of Lisbon. 